\title{
The Correlation between Human Posture and Musculoskeletal Disorder of Upper Extremities among Computer Workers at Indonesian State Owned Enterprises in Surabaya
}

\author{
Lupita Ghilang Laraz ${ }^{1}$, Linda Dewanti ${ }^{{ }^{*}}$, Andriati ${ }^{3}$, Sulistiawati ${ }^{2}$
}

${ }^{1}$ Faculty of Medicine, Universitas Airlangga, Surabaya, Indonesia.

${ }^{2}$ Department of Public Health - Preventive Medicine, Faculty of Medicine, Universitas Airlangga, Surabaya, Indonesia.

${ }^{3}$ Department of Physical Medicine and Rehabilitation, Faculty of Medicine, Universitas Airlangga - Dr. Soetomo General Hospital Surabaya, Indonesia.

A B S T R A C T

Introduction: Computer becomes a highly used and essential tool in daily life. This also applies to occupational level. However, there are risk factors in using the computer within daily life while working, one of them is the posture while working in front of computer. Due to the risk factors, computer workers develop complaint in upper extremities, but they tend to ignore it. The complaint silently decreases their life quality, efficiency, and productivity. This study aimed to find the correlation between human posture and musculoskeletal disorder (MSD).

Methods: This was an observational analytic study, using total sampling technique. The subjects were the computer workers in Indonesian State Owned Enterprises in Surabaya. They were given NMQ for mapping the distribution of complaint. Observational sheets were provided to assess the human posture using NERPA Assessment Worksheet. Spearman's rank method was used to observe the correlation between human posture and MSD.

Result: 112 chosen subjects were involved. Human posture showed large correlation with MSD. This was calculated using alpha value 0.05 for the significance.

Conclusion: There is a correlation between human posture and MSD among computer workers at Indonesian State Owned Enterprises in Surabaya.

* Correspondence: linda-d@fk.unair.ac.id

JUXTA: Jurnal IImiah Mahasiswa Kedokteran Universitas Airlangga

p-ISSN: 1907-3623; e-ISSN: 2684-9453

DOI: 10.20473/juxta.V11/12020.28-31

Open access under Creative Commons Attribution-ShareAlike 4.0 International License

(CC-BY-SA)
ARTICLE INFO

Article history:

Received 02 December 2019

Received in revised form 11 January 2020

Accepted 27 January 2020

\section{Keywords:}

Individual characteristics, Human posture,

Workstation,

Musculoskeletal disorder,

Computer workers. 


\section{Introduction}

Performing occupational work is the basic main thing that most humans do to fulfill their daily needs in life, whether it involves the mental and/or the physical effort to achieve certain purpose. However, unexpected events such as those that will danger the workers and/or the environment sometimes occur by themselves, although some can also be avoided. Human, social, and economic costs of occupational accidents, including injuries, diseases, and major industrial disasters, have long been the cause of concern at all levels, from the individual workplace to the national and international ones. ${ }^{1}$ Nevertheless, as time passes by, the presence of certain technologies has increased the level of safety in occupational work and some efforts of performing the occupational work are not needed as much as it is used to. The technology keeps developing from times to times, facilitating human's need and making human's work easier. Computer is a part of the developing technology that is essential and highly used in most of every aspects of life, including in the occupational level in most companies. However, it still can lead to danger - health problems - for the computer workers, if the behavior of computer usage is not controlled properly, and eventually will interrupt the efficiency and productivity of doing daily activities.

The disorder which acts as the cause of work disruption is characterized by World Health Organization (WHO) in 1985 as a "work-relate" disease, and it is multifactorial to indicate that a number of risk factors (e.g. physical, work organizational, psychosocial, individual, and sociocultural) contribute to cause the disease. One of the health problems that has possibility to occur to computer workers is musculoskeletal disorder (MSD). According to Nunes and McCauley Bush written in Ergonomics - A System Approach on 2012, work-relate musculoskeletal disorder (WMSD) relates with repetitive and demanding working condition, and is a continuation to represent one of the biggest problems in industrialized countries. ${ }^{2}$ The symptoms and complaints of musculoskeletal upper extremities, including neck, shoulder, and arms, are common in the general population among the computer workers, especially in industrialized countries.

The subjects chosen in this research were the computer workers at Indonesian State Owned Enterprises (Badan Usaha Milik Negara/BUMN) in Surabaya. Each of the companies has nearly the same working hours and loads. They are obliged to spend most of the working time using the computer to process a large amount of data. Once there is an electrical disturbance, which will result in inability to use the computer, they will not be able to do their work properly. This is enough to explain how they are really dependent on the computer to complete their work.

This research was planned to be conducted in purpose of supporting former research that has been done in Indonesia regarding specifically to the neck, trunk, and upper extremities WMSD in computer workers. Other than that, there are still many of them who have little awareness towards the ideal human posture while working in front of the computers and choose to ignore the discomfort in their upper extremities. This can be dire for them as they tend to believe that the discomfort will disappear by itself as they have a good quality of rest, however, this will slowly decrease their life quality and eventually will result in decreasing the efficiency and productivity of the work. This is the reason why human posture needs to be measured and known. It is expected to be the caution to prevent further complication in the complaints of MSD.

\section{Methods}

This was an observational analytic study, utilizing a cross-sectional strategy by evaluating human posture as well as MSD of computer workers at Indonesian State Owned Enterprises in Surabaya. Consecutive sampling approach was used in this research, meaning the entire computer workers in the chosen companies who met the inclusion criteria were selected. The inclusion criteria were the computer workers who were willing to be involved as the subjects of this research, whereas the exclusion criteria were the computer workers who had history of musculoskeletal trauma.

The independent variable covers human posture of the computer workers while working in front of the computer. Human postures which were measured include the position of upper arm, lower arm, wrist, neck, and trunk. These were calculated and divided into four types of degree of physical risk factors according to Novel Ergonomic Postural Assessment (NERPA) worksheet.

According to Sanchez-Lite in 2013, NERPA is a modification method of Rapid Upper Limb Assessment (RULA) where it presents changes for the arms, wrist, neck, and trunk by using 3D CAD tool. ${ }^{3}$ Meanwhile, RULA is a survey method developed for use in ergonomics investigations of workplaces where work-related upper limb disorders are reported, according to McAtamney and Nigel Corlett in $1993 .{ }^{4}$ NERPA is quite easy to use since it does not require any advanced tools and is provided by recent technology to visualize for specifically assessing the upper extremities.

In accordance with NERPA worksheet, the computer workers whose NERPA's final score were in the range of 12 were interpreted as having acceptable posture. Whereas those whose NERPA's final score were in the range of 3-4 needed to be investigated further for the posture. The following range of score was $5-6$, meaning the computer workers needed to undergo further investigation along with changing the posture as soon as possible. The last, as well as the highest score, was 7 , in which the computer workers had to be investigated and change the posture immediately.

As for the dependent variable, it includes the presence of musculoskeletal complaint of the computer workers. Nordic Musculoskeletal Questionnaire (NMQ) was used subjectively by the respondents to point out the musculoskeletal complaint in the specific parts of their bodies. NMQ has been applied to a wide range of occupational groups to evaluate musculoskeletal problems, including computer and call center workers based on Crawford in 2007..$^{5}$

Primary data were obtained through assessing human posture using NERPA worksheet and filling out questionnaire using NMQ. Data analysis used univariate and bivariate analysis utilizing Spearman's Rank Correlation at a significance level of $95 \%(\alpha=0.05)$. The statistical test results were said to be significant if the $\rho$ value $<0.05$ and not significant if the $\rho$ value $>0.05$.

\section{Results}

The research was conducted from July to October 2018 at Indonesian State Owned Enterprises in Surabaya. The total number of the computer workers in the chosen companies was 114. Nevertheless, the respondents who met the inclusion criteria were 112, where the rest were included in the exclusion criteria. Table 1 shows the characteristics of the computer workers' posture while working in front of the computer. Table 2 shows MSD of the respondents based on distribution of complaint. Table 3 is the results of bivariate analysis. It is stated that human 
posture and MSD had a $\rho$ value of less than 0.05 . This means human posture has a significant correlation to MSD among computer workers at Indonesian State Owned Enterprises in Surabaya. Furthermore, the correlation coefficient is positive $\left(.538^{* *}\right)$, meaning the variables are in linear correlation. In addition, the significant value $(.000)$ is lower than the alpha value (0.05). These can be interpreted that there is a significant correlation between human postures with obtaining MSD.

Table 1. Characteristics of computer workers' posture while working in front of the computer.

\begin{tabular}{llll}
\hline & Variables & $\mathbf{N}$ & $\%$ \\
\hline \multirow{2}{*}{$\mathbf{A g e}^{\mathbf{1 , 2}}$} & $<25$ years old & 5 & 4.5 \\
& $\geq 25$ years old & 107 & 95.5 \\
\hline \multirow{2}{*}{ Sex } & Male & 71 & 63.4 \\
& Female & 41 & 36.6 \\
\hline \multirow{3}{*}{ Human Posture } & Acceptable & 0 & 0 \\
& Investigate Further & 44 & 39.3 \\
& Investigate Further and Change Soon & 60 & 53.6 \\
& Investigate and Change Immediately & 8 & 7.1 \\
\hline
\end{tabular}

${ }^{1}$ Minimum age: 23 years old; maximum age: 50 years old

${ }^{2}$ Mean \pm SD: $35 \pm 7.7$

Table 2. MSD of the respondents based on distribution of complaint.

\begin{tabular}{|c|c|c|c|}
\hline & Variables & $\mathbf{N}$ & $\%$ \\
\hline \multirow{2}{*}{ Neck } & Absents & 36 & 32.1 \\
\hline & Presents & 76 & 67.9 \\
\hline \multirow{2}{*}{ Shoulder } & Absents & 107 & 95.5 \\
\hline & Presents & 5 & 4.5 \\
\hline \multirow{2}{*}{ Upper Arm } & Absents & 72 & 64.3 \\
\hline & Presents & 40 & 35.7 \\
\hline \multirow{2}{*}{ Lower Arm } & Absents & 103 & 92 \\
\hline & Presents & 9 & 8.1 \\
\hline \multirow{2}{*}{ Trunk } & Absents & 34 & 30.4 \\
\hline & Presents & 78 & 69.6 \\
\hline \multirow{2}{*}{ Elbow } & Absents & 110 & 98.2 \\
\hline & Presents & 2 & 1.8 \\
\hline \multirow{2}{*}{ Wrist } & Absents & 92 & 82.1 \\
\hline & Presents & 20 & 17.9 \\
\hline \multirow{2}{*}{ Hand } & Absents & 108 & 96.4 \\
\hline & Presents & 4 & 3.6 \\
\hline \multirow{2}{*}{ Leg } & Absents & 85 & 75.9 \\
\hline & Presents & 27 & 24.1 \\
\hline
\end{tabular}

Table 3. Bivariate analysis (Spearman's Rank Correlation).

$\mathbf{N}=112 \quad$ Musculoskeletal Disorder

Correlation Coefficient ${ }^{1} \quad \rho$-value ${ }^{2}$

$\begin{array}{lll}\text { Human Posture } & .538^{\star * 3} & .000\end{array}$

\footnotetext{
${ }^{1}$ Correlation Coefficient was in regards of Spearman's Rank Correlation and Cohen, J (1988)

$2 \rho$-value $<0.05=$ significant

${ }^{3 * *}$. Correlation is significant at 0.01 level (2-tailed)
}

\section{Discussion}

According to the study conducted by Eltayeb, et al. in 2009, the mapping complaint was shown that neck complaint in female computer workers had the highest percentage $(24 \%)$ rather than shoulder $(20 \%)$ and arms $(12.1 \%) .^{6}$ Meanwhile, in male computer workers, the complaint in the neck and shoulder had the same amount of percentage $(42 \%)$, and the complaint in the arms appeared to have lower amount of percentage (13.6\%). Complaints of Arm, Neck, and Shoulder (CANS) were recognized in the early seventies as an important cause of work disability according to the research by Prakash, et al. in $2014 .^{7}$ Yasmin, et al. in 2008 found that the highest percentage $(61.3 \%)$ of pain among 305 computer workers in Dhanmondi and Mohammadpur area of Dhaka city was identified in the neck. ${ }^{8}$

In this research, human posture is the final score of the assessment of upper arm, lower arm, wrist, neck, trunk, and leg position in general, based on NERPA Assessment Worksheet. The scoring process of the assessed body parts is standardized based on NERPA method. The final score has range from 1 to 7 with different interpretation.

NERPA final score of 1 or 2 is interpreted as Acceptable. This means human posture of the subjects give 
no risk for obtaining MSD. However, in this research, it happens to be no subjects who have this acceptable posture.

The second one is interpreted as Investigate Further for those who have NERPA final score of 3 or 4 . This means the subjects have minimal risk and need to be investigated further, which will prevent them from obtaining the MSD. In this research, there were 44 subjects or the same as $39.3 \%$ of total subjects who had the score of 3 or 4 .

Next one is NERPA final score of 5 or 6 . This is interpreted as Investigate Further and Change Soon. Based on the interpretation, it means the subjects have moderate risk and need to be investigated further and change the position which put them on risk to prevent MSD. The result of NERPA final score of 5 or 6 happens to have the most subjects on this research (60 subjects or $53.6 \%$ ).

The last one is those who have NERPA final score of 7 . This score is interpreted as Investigate and Change Immediately, meaning the subjects need to be investigated further and have the urgency to change their position which put them on the risk of obtaining MSD. In this research, few of the subjects were at this score (8 subjects or $7.1 \%$ ).

As for the correlation, the respondents who had awkward position on each of the elements had complaint in certain body parts related to the position. The correlation coefficient $\left(.538^{* *}\right)$ is interpreted as having large correlation on each variables compared, in this case the variables are human posture and MSD. Human posture includes upper arm, lower arm, wrist, neck, and trunk. All of the elements are summed up and are correlated with the presence of complaint of MSD which includes the area of neck, shoulder, upper arm, lower arm, trunk, elbow, wrist, hand, and leg. Other than that, the correlation coefficient is positive $\left(.538^{* *}\right)$ which is interpreted as linear correlation, hence when one variable moves higher or lower, other variable moves in the same direction with the same magnitude. The $\rho$ value (.000) is lower than $\alpha$ value (0.05). These can be interpreted that there is a significant correlation between human postures with obtaining MSD.

However, human posture is not the only factor which induces MSD. Individual characteristics and workstation also have high possibility to contribute to the severity level or distribution of complaints that they have been currently suffering from. Also, the habit of doing the stretching during work is noticed since it may affect the quality of the complaint. Other than that, the side jobs of the computer workers may also affect the complaint of MSD depending on what kind of job they work on. ${ }^{9-11}$

Eventually, correct sitting posture should allow for dynamic behavior with many postural changes based on Freudenthal, et al. in 1991. ${ }^{12}$ Training in a sound sitting posture is important for preventing MSD as well as promoting the efficiency of work.

\section{Conclusion}

The value of $\rho=.000$ with the value of $\alpha=0.05$ means that there is a significant correlation between human posture and MSD. However, human posture is not the only factor that plays a role in obtaining MSD. Further research is needed to be conducted on other factors, such as individual characteristics and workstation that can relate to obtaining MSD.

\section{Acknowledgement}

1. The computer workers at the chosen Indonesian State Owned Enterprises in Surabaya.

2. The representative of each chosen Indonesian State Owned Enterprises in Surabaya.

\section{CONFLICT OF INTEREST}

The author stated there is no conflict of interest in this study.

\section{REFERENCES}

1. Alli B. Fundamental Principles of Occupational Health and Safety. 2nd Ed. Geneva: International Labour Office, 2008.

2. Nunes IL and Bush PM. Work-Related Musculoskeletal Disorders Assessment and Prevention. 2012.

3. Sanchez-Lite A, Garcia M, Domingo R and Angel Sebastian M. Novel Ergonomic Postural Assessment Method (NERPA) Using Product-Process Computer Aided Engineering for Ergonomic Workplace Design. PLOS ONE. 2013; 8: E72703.

4. Mcatamney L and Nigel Corlett E. RULA: A Survey Method for the Investigation of Work-Related Upper Limb Disorders. Appl Ergon. 1993; 24: 91-9.

5. Crawford JO. The Nordic Musculoskeletal Questionnaire. Occupational Medicine. 2007; 57: 300-1.

6. Eltayeb S, Staal JB, Hassan A and De Bie RA. Work Related Risk Factors for Neck, Shoulder and Arms Complaints: A Cohort Study among Dutch Computer Office Workers. J Occup Rehabil. 2009; 19: 315-22.

7. Prakash J, Singh V, Prakash J, Bhatty S and Deane A. Computer Usage and Musculoskeletal Disorders Webmedcentral. 2014; 5.

8. Yasmin N, Bhuiyan $M$ and Lahiry S. Related Musculoskeletal Disorders among Computer User. The 9th Southeast Asian Ergonomics Conference. 2008.

9. Jensen C, Ryholt CU, Burr H, Villadsen $E$ and Christensen $\mathrm{H}$. Work-Related Psychosocial, Physical and Individual Factors Associated with Musculoskeletal Symptoms in Computer Users. Work \& Stress. 2002; 16: 107-20.

10. Da Costa BR and Vieira ER. Stretching to Reduce Work-Related Musculoskeletal Disorders: A Systematic Review. J Rehabil Med. 2008; 40: 321-8.

11. Tarwaka. Ergonomi untuk Keselamatan, Kesehatan Kerja Dan Produktivitas. 1st Ed. Surakarta: UNIBA PRESS, 2004.

12. Freudenthal A, Van Riel MPJM, Molenbroek JFM and Snijders CJ. The Effect on Sitting Posture of a Desk with a Ten-Degree Inclination Using an Adjustable Chair and Table. Applied Ergonomics. 1991; 22: 329-36. 